\title{
Optimasi pembelajaran daring siswa dan guru di masa pandemi Covid-19 menggunakan Google Classroom pada PKBM Bhakti Asih
}

\author{
Achmad Solichin ${ }^{1, *}$, Dwi Kristanto ${ }^{2}$, Gandung Triyono ${ }^{3}$ \\ ${ }^{1,3}$ Program Studi Teknik Informatika, Fakultas Teknologi Informasi \\ ${ }^{2}$ Program Studi Manajemen, Fakultas Ekonomi dan Bisnis \\ Universitas Budi Luhur \\ Email Korespondensi: *achmad.solichin@budiluhur.ac.id
}

Received May 7, 2021; Revised May 26, 2021; Accepted June 11, 2021

\begin{abstract}
Abstrak
Pandemi Covid-19 yang terjadi secara global mengakibatkan pemerintah Indonesia mengeluarkan kebijakan belajar di rumah bagi seluruh institusi pendidikan di semua jenjang. Kebijakan belajar di rumah menjadi tantangan tersendiri bagi penyelenggara pendidikan yang belum memiliki infrastruktur pembelajaran daring, termasuk PKBM Bhakti Asih. Selain itu, kesiapan guru dan siswa juga menjadi kendala dalam penerapan pembelajaran daring. Kegiatan pengabdian kepada masyarakat (abdimas) bertujuan untuk membantu PKBM Bhakti Asih dalam mengatasi permasalahan tersebut. Langkah pelaksanaan abdimas meliputi identifikasi masalah menggunakan metode observasi dan wawancara; analisis solusi dengan melakukan studi literatur; perencanaan kegiatan; pelaksanaan kegiatan; dan evaluasi kegiatan. Kegiatan abdimas ini berupa pelatihan bagi guru dan siswa untuk menggunakan Google Classroom dalam rangka mendukung proses belajar-mengajar secara daring di masa pandemi Covid-19. Outcome dari kegiatan abdimas ini berupa peningkatan kompetensi guru dan siswa dalam penggunaan Google Classroom, serta kesiapan PKBM Bhakti Asih dalam melaksanakan pembelajaran daring. Selain itu, berdasarkan penilaian peserta kegiatan, pelaksanaan kegiatan ini dinilai sangat baik dan peserta merasa puas dengan narasumber pelatihan.

Kata Kunci: pandemi; pelatihan; pembelajaran daring; siswa dan guru; google classroom
\end{abstract}

\begin{abstract}
The Covid-19 pandemic that occurred globally resulted in the Indonesian government issuing a "learning from home" policy for all educational levels. It is a challenge for education institutions who do not yet have online learning infrastructure, including the PKBM Bhakti Asih. In addition, the readiness of teachers and students is also an obstacle in implementing online learning. This community service activities aim to assist PKBM Bhakti Asih in overcoming these problems. The steps for implementing the activity include identifying problems using the observation and interview methods; solution analysis by conducting literature studies; activity planning; implementation of activities; and evaluation of activities. This community service activity is in the form of training for teachers and students to use Google Classroom in order to support the online teaching and learning process during the Covid-19 pandemic. The outcome of this activity was in the form of increasing the competence of teachers and students in using Google Classroom, as well as the readiness of PKBM Bhakti Asih in implementing online learning. In addition, based on the assessment of the activity participants, the implementation of this activity was considered very good and the participants were satisfied with the trainers.
\end{abstract}

Keywords: pandemic; training; online learning; student and teacher;google classroom

\section{PENDAHULUAN}

Pusat Kegiatan Belajar Masyarakat (PKBM) adalah suatu wadah yang menyediakan informasi dan kegiatan belajar bagi setiap warga masyarakat agar mereka lebih berdaya. sepanjang hayat. Wadah ini adalah milik masyarakat dikelola, dari, oleh, dan untuk masyarakat. Secara umum, Pusat Kegiatan Belajar Masyarakat memiliki posisi strategis dalam program penyelenggaran pendidikan nonformal atau dulu dikenal dengan pendidikan luar sekolah. Hal ini ditunjukan dengan adanya UU Nomor 20 tahun 2003 tentang sistem pendidikan Nasional yang menetapkan bahwa PKBM merupakan salah satu satuan pendidikan non formal .

Pada perkembangannya, PKBM tidak hanya menunjukkan hasil secara kuantitas tetapi juga secara kualitas. Penyelenggaraan PKBM makin memberikan gambaran bahwa masyarakat tidak hanya menjadi sasaran dari kelompok warga belajar tetapi juga masyarakat mampu melakukan pengelolaan program pendidikan luar sekolah sesuai dengan kebutuhannya. PKBM juga dapat dijadikan medium bersama oleh 
pemerintah dan masyarakat untuk saling menguatkan dan mengoptimalkan peran masing-masing dalam pengelolaan program pendidikan nonformal.

Pandemi Covid-19 telah terjadi di seluruh dunia, termasuk di Indonesia. Saat ini di seluruh dunia lebih dari 156 juta pasien terkonfirmasi positif dengan total kematian lebih dari 3,2 juta orang [1]. Kondisi tersebut mengakibatkan pemerintah Indonesia mengeluarkan kebijakan dan himbauan agar masyarakat bekerja di rumah, belajar di rumah dan beribadah di rumah. Instansi pemerintah, kantor-kantor, pabrik, perusahaan, perguruan tinggi, dan sekolah-sekolah diminta untuk mengurangi aktivitasnya. Bahkan beberapa diantaranya diminta untuk tutup. Salah satu dampak dari kebijakan pemerintah tersebut adalah di bidang pendidikan, yang mana seluruh siswa diharuskan belajar di rumah.

Kebijakan belajar di rumah tentunya memiliki tantangan tersendiri bagi penyelenggara pendidikan, termasuk PKBM Bhakti Asih, Ciledug. PKBM Bhakti Asih merupakan salah satu sekolah nonformal beralamat di Jl. Raden Fatah RT.003/10 No. 7 Ciledug Kota Tangerang, Sudimara Barat. Beberapa institusi pendidikan yang telah terbiasa menyelenggarakan pembelajaran daring tentu akan lebih mudah. Namun bagi sekolah yang belum memiliki fasilitas tersebut, termasuk PKBM Bhakti Asih, tentunya akan menjadi masalah yang harus diselesaikan. Selain itu, kesiapan guru dan siswa dalam menggunakan teknologi pembelajaran daring juga menjadi kendala.

Salah satu layanan gratis yang diberikan oleh Google dalam pembelajaran daring adalah Google Classroom [2]. Layanan tersebut memberikan kemudahan bagi penggunanya karena bersifat gratis dan tidak memerlukan instalasi atau perangkat khusus. Google Classroom dapat diakses secara daring menggunakan akun Google yang juga dapat diperoleh secara gratis. Pada kegiatan pengabdian kepada masyarakat ini, telah diselenggarakan pelatihan bagi guru dan siswa untuk menggunakan Google Classroom dalam rangka mendukung proses belajar-mengajar secara daring di masa pandemi Covid-19. Dengan kegiatan pengabdian kepada masyarakat (abdimas) ini, proses pembelajaran dapat tetap berlangsung secara baik dan optimal walaupun harus diselenggarakan secara daring.

Berikut ini beberapa manfaat atau fitur unggulan yang dimiliki oleh Google Classroom [2], [3]:

- Dapat disiapkan dengan mudah. Pengajar dapat menyiapkan kelas dan mengundang siswa serta pengajar. Di halaman tugas kelas, siswa dan pengajar dapat berbagi informasi, tugas, pertanyaan, dan materi.

- Menghemat waktu dan kertas. Pengajar dapat membuat kelas, memberikan tugas, berkomunikasi, dan melakukan pengelolaan, semuanya di satu tempat.

- Pengelolaan yang lebih baik. Siswa dapat melihat tugas di halaman tugas, di aliran kelas, atau di kalender kelas. Semua materi kelas otomatis disimpan dalam folder Google Drive.

- Penyempurnaan komunikasi dan masukan. Pengajar dapat membuat tugas, mengirim pengumuman, dan memulai diskusi kelas secara langsung. Siswa dapat berbagi materi antara satu sama lain dan berinteraksi dalam aliran kelas atau melalui email. Pengajar juga dapat melihat dengan cepat siapa saja yang sudah dan belum menyelesaikan tugas, serta langsung memberikan nilai dan masukan secara real-time.

- Dapat berfungsi dengan berbagai aplikasi lain. Classroom dapat dihubungkan dengan Google Dokumen, Kalender, Gmail, Drive, dan Formulir.

- Terjangkau, gratis dan aman. Classroom disediakan gratis untuk sekolah, lembaga nonprofit, dan perorangan. Classroom tidak berisi iklan dan tidak pernah menggunakan konten atau data siswa untuk tujuan periklanan.

- Mobile Friendly - Google Classroom dapat diakses melalui perangkat smartphone menggunakan peramban atau dengan memasang aplikasi khusus Google Classroom yang tersedia di Google Playstore.

Dengan berbagai kelebihan dan fitur yang dimiliki oleh Google Classroom tersebut, banyak institusi pendidikan memilih Google Classroom sebagai platform pembelajaran daringnya. Bagi guru atau pengajar, Google Classroom juga mudah digunakan dan dapat diakses melalui jaringan internet dengan kecepatan rendah [3]. Sementara itu, siswa yang menggunakan Google Classroom juga berpendapat yang sama, bahwa mudah digunakan dan efektif [3]. Menurut penelitian lainnya, penggunaan Google Classroom bagi mahasiswa juga terbukti dapat diterima dengan baik [4]. Faktor dominan yang mempengaruhi penerimaan Google Classroom adalah kegunaan (usefullness) dan kemudahannya (easy of use).

Saat ini, banyak instansi pendidikan dan non pendidikan yang telah menggunakan Google Classroom (GC) sebagai salah satu sarana pembelajaran. Tabel 1 menyajikan beberapa penelitian yang membahas implementasi Google Classroom di berbagai instansi.

Tabel 1. Penggunaan Google Classroom di Berbagai Instansi Pendidikan

\begin{tabular}{ccllll}
\hline Tahun & Penelitian & \multicolumn{2}{c}{ Pemanfaatan Google Classroom } & Jenis Instansi \\
\hline 2016 & {$[5]$} & GC digunakan sebagai media pembelajaran & di & Sekolah \\
2017 & {$[6]$} & Sekolah Dasar & GC untuk kelas virtual pada SMK & Sekolah \\
2018 & {$[7]$} & $\begin{array}{l}\text { GC sebagai media pembelajaran di SMK Negeri 1 } \\
\text { Bangkinang }\end{array}$ & Sekolah
\end{tabular}




$\begin{array}{lcll}2019 & {[8]} & \begin{array}{l}\text { GC untuk pembelajaran matakuliah Ilmu Budaya } \\ \text { Dasar di Universitas Borneo Tarakan }\end{array} & \text { Perguruan Tinggi } \\ 2019 & {[9]} & \begin{array}{l}\text { GC digunakan untuk pembelajaran mahasiswa } \\ \text { jurusan sistem komputer STMIK STIKOM Indonesia }\end{array} & \text { Perguruan Tinggi } \\ 2019 & {[10]} & \begin{array}{l}\text { GC sebagai Media Pembelajaran Online di } \\ \text { Universitas Dian Nuswantoro }\end{array} & \text { Perguruan Tinggi } \\ 2020 & {[11]} & \begin{array}{l}\text { GC sebagai sarana pembelajaran matematika } \\ \text { GC untuk pembelajaran siswa Kelas XI IPS 4 SMAN }\end{array} & \text { Sekolah } \\ 2020 & {[12]} & \begin{array}{l}\text { 1 Bangkinang Kota } \\ \text { GC untuk pembelajaran di perguruan tinggi agama }\end{array} & \text { Perguruan Tinggi } \\ 2020 & {[13]} & \begin{array}{l}\text { islam } \\ \text { GC untuk pembelajaran sistem peredaran darah } \\ \text { manusia pada SMA Buq'atun Mubarakah Makassar } \\ \text { GC untuk pembelajaran matematika pada SMA N 1 }\end{array} & \text { Sekolah } \\ 2021 & {[14]} & \text { Maumere } & \\ 2021 & {[15]} & \end{array}$

Kegiatan pengabdian kepada masyarakat ini bertujuan untuk mempersiapkan dan melatih guru dan siswa dalam menggunakan media pembelajaran daring berbasis Google Classroom sebagai alternatif media pembelajaran di masa Pandemi Covid-19. Pada kegiatan yang merupakan salah satu wujud nyata dari Tridharma Perguruan Tinggi ini, kami ingin membantu masyarakat di lingkungan PKBM Bhakti Asih untuk meningkatkan kinerja guru-guru dalam metode pembelajaran berbasis elearning. Dengan kegiatan ini, dapat memberikan manfaat yang positif bagi peningkatan kualitas sumber daya manusia dan kualitas proses pembelajaran di sekolah.

\section{METODE}

Gambar 1 menunjukkan metode pelaksanaan kegiatan pengabdian kepada masyarakat. Kegiatan pengabdian kepada masyarakat (abdimas) ini diawali dengan proses identifikasi permasalahan di PKBM Bhakti Asih sebagai mitra kegiatan. Tahapan identifikasi masalah bertujuan untuk mengidentifikasi secara menyeluruh permasalahan yang dialami oleh mitra. Metode identifikasi masalah yang digunakan adalah observasi dan wawancara yang dilaksanakan dengan perwakilan pihak pengelola, guru dan siswa. Wawancara dilakukan melalui media daring sebagai bentuk kepatuhan atas protokol kesehatan.

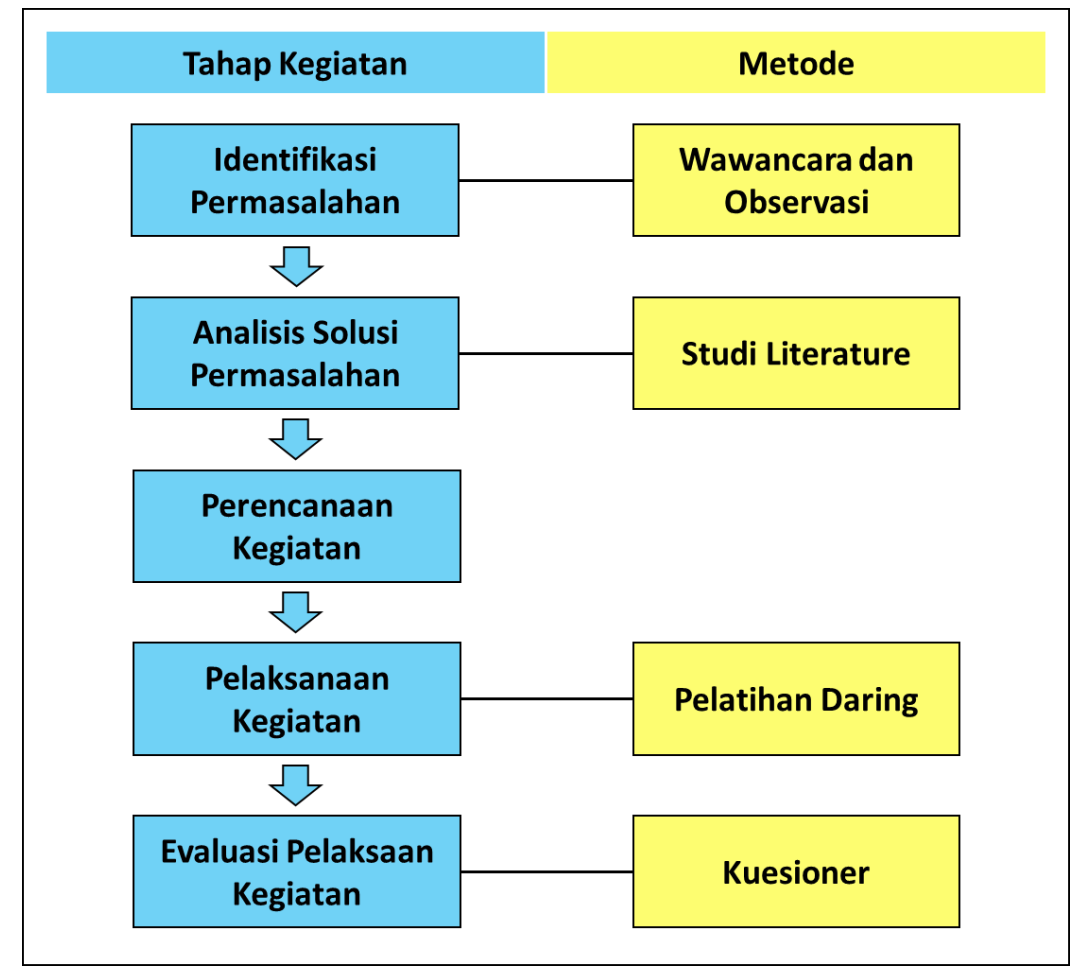

Gambar 1. Metode Pelaksanaan Kegiatan 
Setelah berhasil melakukan identifikasi masalah, selanjutnya tim pelaksana abdimas melakukan analisis solusi atas permasalahan yang dihadapi oleh mitra. Analisis solusi didasarkan pada metode kepustakaan atau studi literature sehingga diperoleh rancangan solusi yang tepat sasaran dan memiliki dasar keilmuan yang kuat. Berdasarkan rancangan solusi, selanjutnya dilakukan perencanaan kegiatan abdimas baik dari sisi waktu, media maupun perangkat pendukung kegiatan. Dari sisi peserta, sasaran kegiatan ini melibatkan guru dan siswa. Namun demikian, pada kegiatan ini tidak dilakukan pembagian waktu pelatihan, artinya pelatihan untuk guru dan siswa dilakukan secara bersama-sama. Hal tersebut bertujuan agar terjadi interaksi langsung antara guru dan siswa.

Tahap berikutnya adalah pelaksanaan kegiatan. Pelaksaan kegiatan berupa pelatihan yang diselenggarakan secara daring menggunakan aplikasi video conference. Bentuk pelaksanaan pelatihan meliputi penyampaian teori oleh narasumber dan dilanjutkan dengan praktek dan tanya jawab. Metode kegiatan pelatihan ini dilakukan berdasarkan pendekatan proses pembelajaran teori dan pembelajaran praktek. Setelah pelaksanaan kegiatan, tahap selanjutnya adalah evaluasi pelaksanaan kegiatan yang melibatkan peserta pelatihan. Evaluasi bertujuan untuk mengukur kualitas pelaksanaan kegiatan baik dari sisi penyelenggaraan maupun narasumber kegiatan.

\section{HASIL DAN PEMBAHASAN}

Tahap pertama dari pelaksanaan kegiatan pengabdian kepada masyarakat ini adalah identifikasi masalah yang dilanjutkan dengan penentuan solusi permasalahan. Gambar 2 menampilkan kerangka berpikir penyelesaian permasalahan pada mitra kegiatan abdimas. Dengan menyusun kerangka berpikir, maka kegiatan pengabdian kepada masyarakat akan lebih tepat sasaran dan bermanfaat bagi mitra kegiatan. Secara umum, permasalahan yang terjadi pada mitra diakibatkan oleh situasi eksternal yaitu kebijakan pembatasan aktivitas pembelajaran oleh Pemerintah sebagai upaya untuk menekan penyebaran Covid-19. Berdasarkan hasil analisis solusi dengan melakukan studi kepustakaan serta wawancara dengan pihak terkait, maka ditetapkan solusi terbaik dalam mengatasi permasalahan mitra adalah dengan penerapan pembelajaran menggunakan Google Classroom.
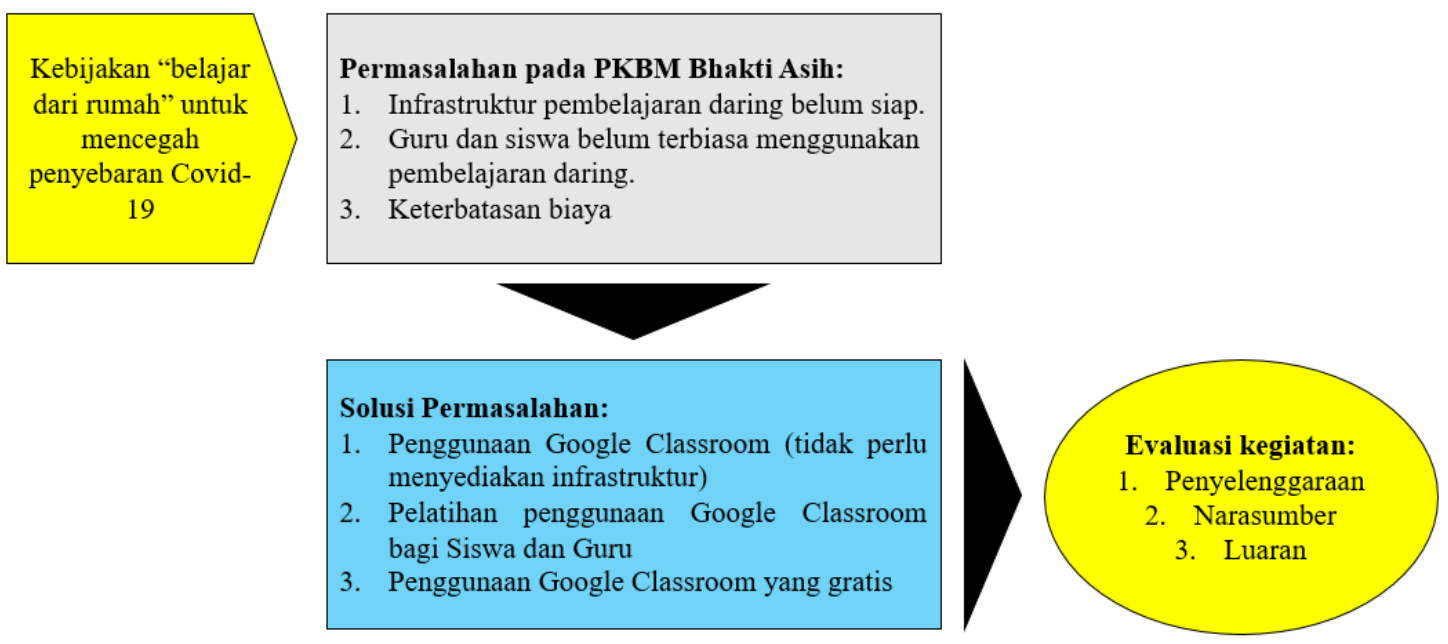

Gambar 2. Kerangka Pikir Penyelesaian Masalah

Tabel 2 menyajikan hubungan antara permasalahan dan solusi dari permasalahan yang berhasil diidentifikasi melalui kegiatan pengabdian kepada masyarakat ini.

Tabel 2. Permasalahan dan Solusi

\begin{tabular}{clll}
\hline No & Permasalahan & Solusi & \\
\hline 1 & Metode pembelajaran masih & Metode pembelajaran daring dapat \\
menggunakan metode konvensional & diterapkan karena dapat dilakukan di rumah \\
(tatap muka) tidak dapat dilakukan pada & dengan memanfaatkan jaringan internet.
\end{tabular}


Optimasi pembelajaran daring siswa dan guru di masa pandemi Covid-19 menggunakan Google Classroom....

\begin{tabular}{clrl}
\hline No & Permasalahan & Solusi & \\
\hline 3 & Sumber daya manusia (guru mata & Diberikan pelatihan dengan mengedepankan \\
& pelajaran) dan siswa belum siap (belum & sisi praktis dibanding teori, untuk \\
& memahami) dalam menggunakan sistem & memberikan pemahaman kepada guru dan \\
pembelajaran daring berbasis Google & siswa dalam menggunakan sistem \\
& Classroom. & pembelajaran daring berbasis Google \\
& & Classroom \\
\hline
\end{tabular}

Pelaksanaan kegiatan pelatihan dalam rangkaian kegiatan pengabdian kepada masyarakat berjalan dengan lancar. Kegiatan pelatihan dilaksanakan pada hari Rabu, 29 Juli 2020 secara daring karena masih berada di masa pandemi Covid-19. Pelatihan dilaksanakan menggunakan platform Zoom Cloud Meeting. Peserta yang hadir dalam pelatihan sebanyak 21 peserta yang terdiri dari 19 orang siswa dan 2 orang guru.

Materi yang disampaikan dalam pelatihan ini secara umum mengenai penggunaan Google Classroom dalam rangka mendukung pembelajaran daring di PKBM Bhakti Asih. Google Classroom merupakan salah satu platform pembelajaran yang dipilih karena paling sesuai dengan kondisi dan kebutuhan PKBM Bhakti Asih. Tabel 3 menyajikan beberapa materi pokok yang disampaikan pada kegiatan abdimas ini. Beberapa materi yang disampaikan pada saat pelatihan antara lain bagaimana mengaktifkan dan login ke Google Classroom, membuat kelas baru, mengunggah materi pelajaran, mengundang dan mengatur siswa, interaksi guru-siswa, menyelenggarakan tugas atau quiz, mengunggah atau mengerjakan tugas dan quiz, serta bagaimana melakukan penilaian.

Tabel 3. Materi Pelatihan

\begin{tabular}{|c|c|c|}
\hline No & Modul & Sub-modul \\
\hline 1 & Mempersiapkan Kelas & $\begin{array}{l}\text { - Membuat kelas baru } \\
\text { - Mengubah tampilan kelas (tema) } \\
\text { - Menambahkan informasi umum terkait kelas } \\
\text { - Mendapatkan kode kelas }\end{array}$ \\
\hline 2 & $\begin{array}{l}\text { Mempersiapkan Bahan Ajar } \\
\text { (Materi) }\end{array}$ & $\begin{array}{l}\text { - Menambahkan topik / materi baru } \\
\text { - Mengunggah bahan (materi) ajar } \\
\text { - Menambahkan materi video dari Youtube } \\
\text { - Merekam video kuliah dengan Google Classroom } \\
\text { - } \text { app (IOS/Android) }\end{array}$ \\
\hline 3 & Mengelola Siswa & $\begin{array}{l}\text { - } \text { Mengundang siswa melalui kode kelas } \\
\text { - } \text { Mengundang siswa melalui email } \\
\text { - } \text { Menampilkan daftar siswa }\end{array}$ \\
\hline 4 & Interaksi Guru dan Siswa & $\begin{array}{l}\text { - } \text { Mengirimkan email ke salah satu siswa } \\
\text { - } \text { Mengirimkan email ke seluruh siswa } \\
\text { - } \text { Berdiskusi melalui fitur komentar }\end{array}$ \\
\hline 5 & Tugas dan Penilaian & $\begin{array}{l}\text { - } \text { Membuat tugas } \\
\text { - } \text { Siswa mengerjakan tugas } \\
\text { - } \quad \text { Penilaian tugas oleh guru } \\
\end{array}$ \\
\hline
\end{tabular}

Sementara itu, Gambar 3 menampilkan dokumentasi penyampaian materi pelatihan ke peserta yang terdiri dari guru dan siswa. Setelah paparan dari narasumber, peserta diberikan kesempatan untuk bertanya dan berdiskusi. Peserta juga diberikan kesempatan mencoba dan praktek langsung melakukan pembelajaran dengan Google Classroom. 


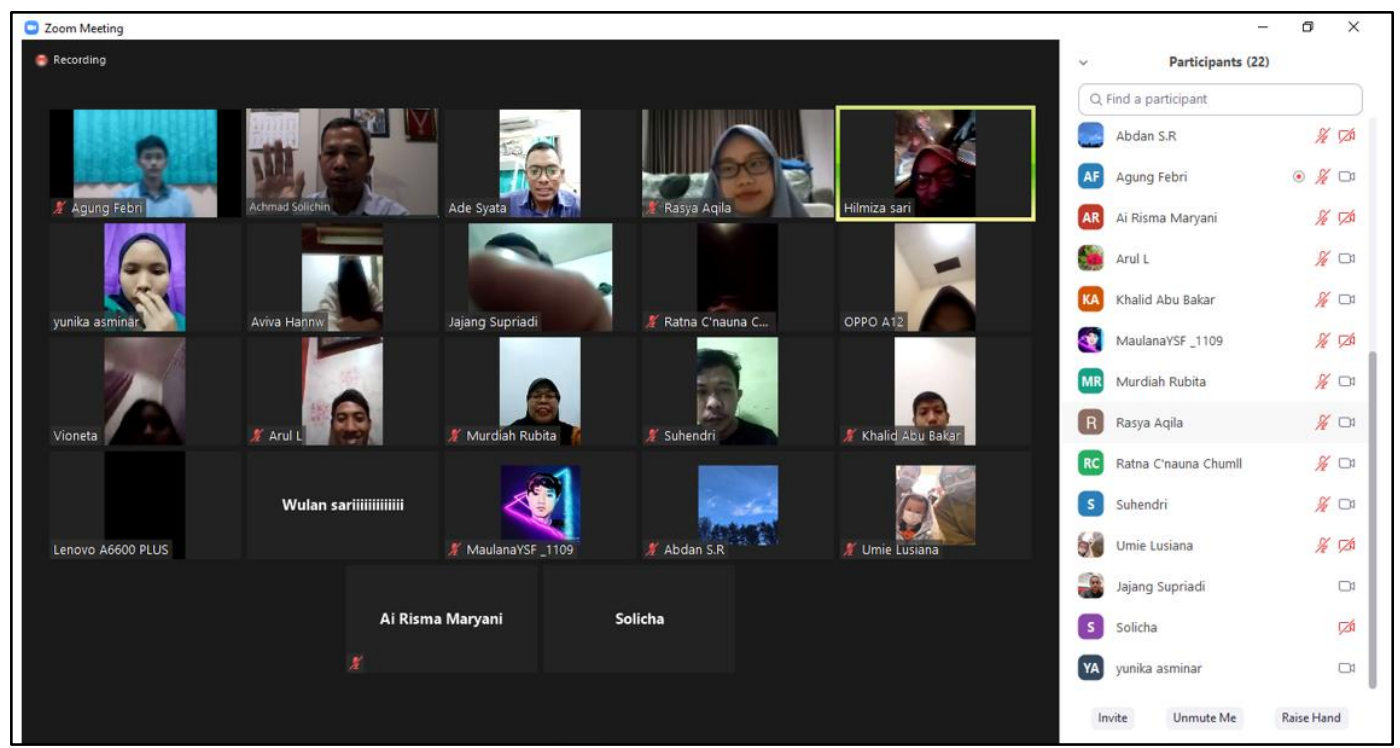

Gambar 3. Dokumentasi Kegiatan Pelatihan

Evaluasi pelaksanaan kegiatan dilakukan dengan metode angket atau kuesioner yang diisi oleh seluruh peserta pelatihan secara daring pada akhir sesi kegiatan. Instrumen kuesioner terdiri 11 pernyataan yang terbagi dalam 2 (dua) bagian, yaitu untuk mengevaluasi penyelenggaraan kegiatan secara umum dan untuk mengevaluasi narasumber pelatihan. Pada setiap pernyataan, responden mengisi skala likert yang bernilai 1 (tidak baik) hingga 5 (sangat baik).

Berdasarkan hasil evaluasi penyelenggaraan pelatihan yang telah dilakukan, diperoleh kesimpulan bahwa pihak PKBM Bhakti Asih, baik siswa maupun guru, dapat merasakan manfaat atas pelatihan pembelajaran daring berbasis Google Classroom yang telah dilakukan. Peserta yang antusias mengikuti pelatihan menunjukkan bahwa materi yang disampaikan cukup menarik. Responden memberikan nilai 4,75 dalam rentang 1-5 dalam hal manfaat materi pelatihan bagi peserta. Error! Reference source not found.Gambar 4 menunjukkan hasil evaluasi penyelenggaraan pelatihan yang diperoleh menggunakan metode kuesioner.

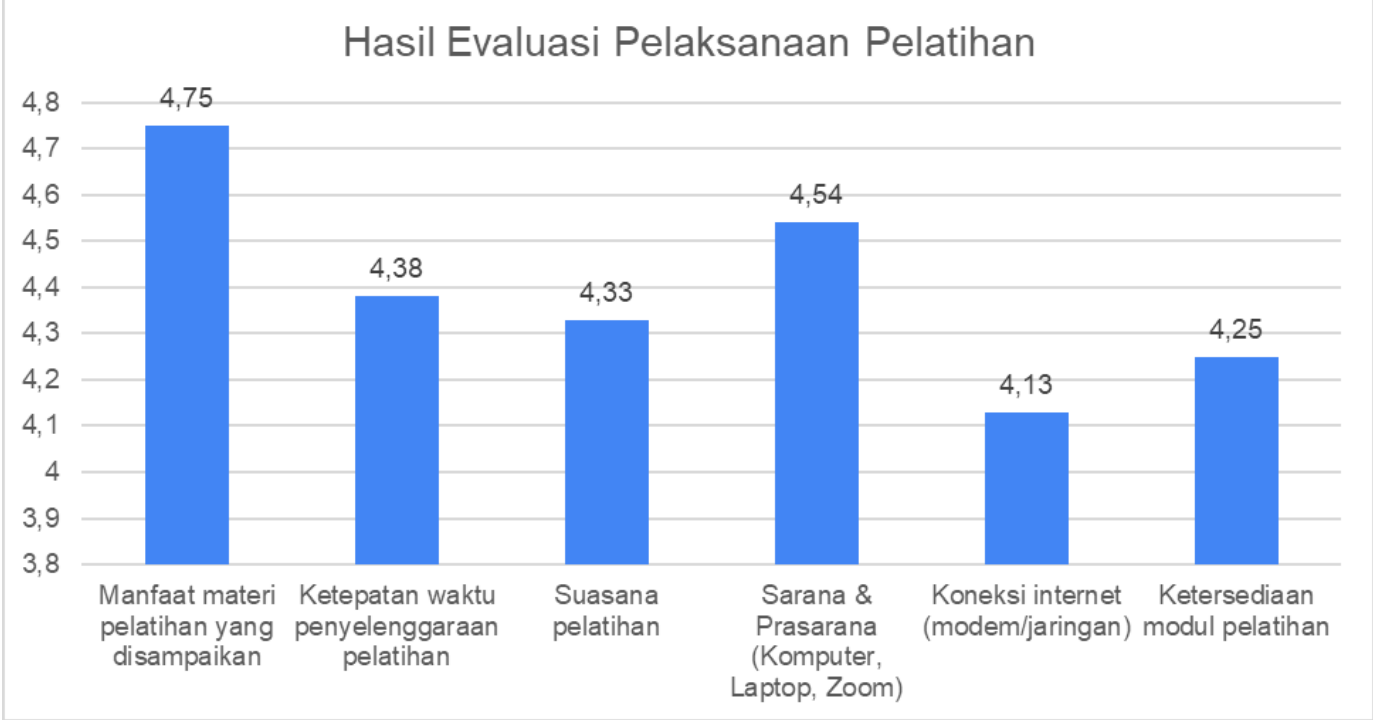

Gambar 4. Hasil Evaluasi Pelaksanaan Pelatihan

Hal-hal yang masih perlu diperbaiki dari kegiatan ini adalah koneksi internet atau jaringan yang memperoleh nilai rata-rata sebesar 4,13. Hal tersebut dapat dipahami karena selama pelatihan berlangsung, beberapa kali komunikasi menggunakan Zoom Cloud Meeting terkendala oleh lambatnya koneksi internet. Peserta yang mengikuti pelatihan dari rumah atau tempat kerjanya masing-masing memiliki kecepatan koneksi yang berbeda-beda. Secara umum, penilaian peserta pelatihan terhadap penyelenggaraan pelatihan dalam kategori sangat baik dengan nilai 4,40 dalam rentang 1-5.

Selain itu, berdasarkan penilaian peserta pelatihan terhadap narasumber pelatihan, secara umum peserta puas dengan narasumber pelatihan dengan nilai 4,52 dalam rentang 1-5. Responden pelatihan memberikan nilai tertinggi pada komponen penguasaan materi narasumber, yaitu sebesar 4,63. Sementara itu, nilai 
terrendah adalah dari sisi penyampaikan materi. Hal tersebut mungkin disebabkan karena kurang lancarnya koneksi internet yang membuat penjelasan materi terkadang tidak diterima dengan baik. Error! Reference source not found. menampilkan grafik hasil evaluasi terhadap narasumber pelatihan.

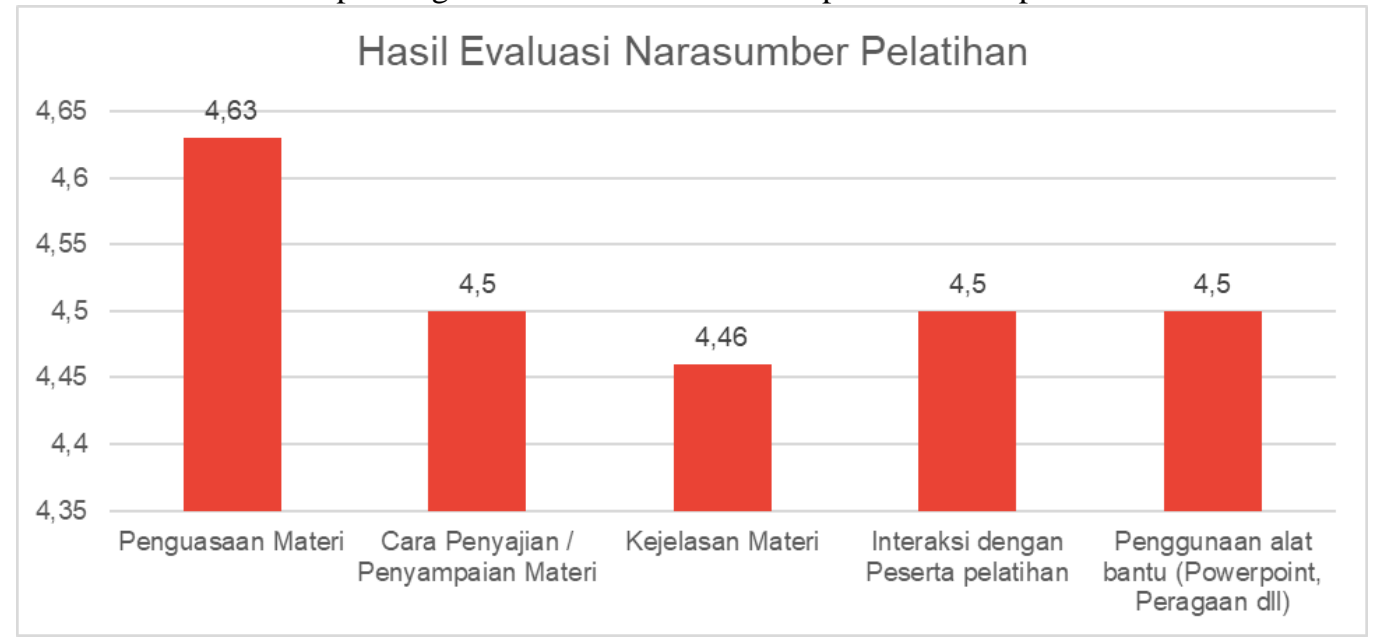

Gambar 5. Hasil Evaluasi Narasumber Pelatihan

Selain evaluasi terhadap pelatihan dan narasumber, dilakukan diskusi dengan guru dan siswa terkait pelaksanaan pelatihan dan materi pelatihan. Guru dan siswa mengharapkan bahwa Google Classroom dapat diterapkan sebagai sarana pembelajaran daring di PKBM Bhakti Asih, terutama selama kondisi pandemi Covid-19. Peserta pelatihan menilai secara umum Google Classroom dapat digunakan dengan mudah.

\section{KESIMPULAN}

Kegiatan pengabdian kepada masyarakat ini telah berhasil terlaksana dengan baik dan lancar. Kegiatan pelatihan dilaksanakan dengan media Zoom Cloud Meeting. Materi pelatihan yang disampaikan bagi peserta pelatihan dari PKBM Bhakti Asih meliputi materi Google Classroom sebagai salah satu sarana pembelajaran daring yang dapat digunakan di PKBM Bhakti Asih. Saat ini, Indonesia masih dalam kondisi pandemi Covid19 sehingga belum memungkinkan untuk dilaksanakan proses belajar-mengajar secara tatap muka. Oleh karena itu, penggunaan Google Classroom dapat membantu proses pembelajaran menjadi lebih optimal dan lebih efektif.

Berdasarkan hasil evaluasi terhadap penyelenggaraan kegiatan, kualitas kegiatan perlu ditingkatkan penyelenggaraannya di masa mendatang. Beberapa saran untuk pelaksanaan kegiatan pengabdian kepada masyarakat (abdimas) di masa mendatang, antara lain:

a. Sarana dan prasarana pelatihan seperti koneksi internet dan perangkat yang digunakan perlu dipersiapkan dengan lebih matang demi kelancaran proses pelatihan.

b. Peserta pelatihan menilai bahwa keberadaan modul pelatihan sangatlah penting, sehingga diharapkan di masa mendatang, modul pelatihan dapat diberikan ke peserta sebelum pelaksanaan pelatihan.

c. Narasumber pelatihan agar lebih mempertimbangkan cara penyampaian materi serta dapat memastikan bahwa seluruh peserta menerima penjelasan dengan baik.

\section{DAFTAR PUSTAKA}

[1] Center for Systems Science and Engineering, "COVID-19 Dashboard," https://gisanddata.maps.arcgis.com/, 2021. [Online].

Available:

[2] Google Classroom, “Tentang Classroom," support.google.com, 2020. [Online]. Available: https://support.google.com/edu/classroom/answer/6020279?hl=id\&authuser=3\&ref_topic=7175444.

[3] S. Iftakhar, "Google classroom: What works and how?," J. Educ. Soc. Sci., vol. 3, no. Feb, pp. 12-18, 2016.

[4] R. A. S. Al-Maroof and M. Al-Emran, "Students acceptance of google classroom: An exploratory study using PLS-SEM approach," Int. J. Emerg. Technol. Learn., vol. 13, no. 6, pp. 112-123, 2018.

[5] V. D. Wicaksono and P. Rachmadyanti, "Pembelajaran Blended Learning melalui Google Classroom di Sekolah Dasar," in Seminar Nasional Pendidikan PGSD UMS \& HDPGSDI Wilayah Timur, 2016, pp. 513-521.

[6] F. I. Gunawan and S. G. Sunarman, "Pengembangan Kelas Virtual Dengan Google Classroom Dalam Keterampilan Pemecahan Masalah (Problem Solving) Topik Vektor Pada Siswa Smk Untuk Mendukung Pembelajaran," in Prosiding Seminar Nasional Etnomatnesia, 2017, pp. 340-348. 
[7] Soni et al., "Optimalisasi Pemanfaatan Google Classroom Sebagai Media Pembelajaran Di SMK Negeri 1 Bangkinang," J. Pengabdi. Untuk Mu NegeRI, vol. 2, no. 1, pp. 17-20, 2018.

[8] D. I. Savitri, "Penggunaan Pembelajaran 4.0 Berbantuan Aplikasi Google Classroom Dan Google Form Dalam Mata Kuliah Ilmu Sosial Budaya Dasar," J. Borneo Sintek, vol. 2, no. 1, pp. 20-25, 2019.

[9] N. Maharani and K. S. Kartini, "Penggunaan google classroom sebagai pengembangan kelas virtual dalam keterampilan pemecahan masalah topik kinematika pada mahasiswa jurusan sistem komputer," PENDIPA J. Sci. Educ., vol. 3, no. 3, pp. 167-173, 2019.

[10] S. A. Hapsari and H. Pamungkas, "Pemanfaatan Google Classroom sebagai Media Pembelajaran Online di Universitas Dian Nuswantoro,” WACANA, vol. 18, no. 2, pp. 225-233, 2019.

[11] N. Nurani, D. Uswatun, and L. Maula, "Analisis Proses Pembelajaran Matematika Berbasis Daring Menggunakan Aplikasi Google Classroom Pada Masa Pandemi Covid-19," J. PGSD, vol. 6, no. 1 SE-Articles, Jul. 2020.

[12] P. Umairah and Zulfah, "Peningkatan Motivasi Belajar Menggunakan ' Google Classroom' Ditengah Pandemi Covid-19 Pada Peserta Didik Kelas XI IPS 4 SMAN 1 Bangkinang Kota,” J. Educ., vol. 02, no. 03, pp. 275-285, 2020.

[13] A. Rusdiana, M. Sulhan, I. Z. Arifin, and U. A. Kamludin, "Penerapan Model POE2WE Berbasis Blended Learning Google Classroom Pada Pembelajaran Masa WFH Pandemic Covid-19," in Karya Tulis Ilmiah (KTI) Masa WFH Covid-19 UIN SGD Bandung, 2020, pp. 1-10.

[14] M. Jannah and Nurdiyanti, "Pengaruh Pembelajaran Online Berbantuan Google Classroom Terhadap Hasil Belajar Siswa SMA pada Materi Sistem Peredaran Darah pada Manusia," JRIP J. Ris. dan Inov. Pembelajaran, vol. 1, no. 1 , pp. 75-84, 2021.

[15] A. E. Longa, "Penggunaan Aplikasi Google Classroom dalam Upaya Meningkatkan Hasil Belajar Matematika Pada Siswa Kelas X Ips 3 SMA Negeri 1 Maumere,” JOTE J. Teach. Educ., vol. 2, no. 2, pp. 49-57, 2021. 